\title{
Radiation-Induced Sarcomas of the Head and Neck: A Systematic Review
}

\author{
Andrés Coca-Pelaz (D) - Antti A. Mäkitie (D) - Primož Strojan • \\ June Corry · Avraham Eisbruch · Jonathan J. Beitler · Sandra Nuyts • \\ Robert Smee · Johannes A. Langendijk · William M. Mendenhall • \\ Cesare Piazza $\cdot$ Alessandra Rinaldo (D) - Alfio Ferlito (D)
}

Received: October 6, 2020 / Accepted: October 28, 2020 / Published online: November 13, 2020

(c) The Author(s) 2020

\begin{abstract}
Introduction: As a result of the increased use of radiotherapy (RT) and improved long-term overall survival of patients with cancers of the head and neck $(\mathrm{HN})$, the frequency of radiationinduced sarcomas of the head and neck (RISHN) may be increasing. The main objective of this systematic review was to determine the existing
\end{abstract}

This article was written by members of the International Head and Neck Scientific Group (www.IHNSG.com).

A. Coca-Pelaz $(\square)$

Department of Otolaryngology, Hospital

Universitario Central de Asturias-University of

Oviedo, Instituto de Investigación Sanitaria del

Principado de Asturias, IUOPA, CIBERONC, Oviedo,

Asturias, Spain

e-mail: acocapelaz@yahoo.es

A. A. Mäkitie

Department of Otorhinolaryngology, Head and

Neck Surgery, University of Helsinki and Helsinki

University Hospital, Helsinki, Finland

P. Strojan

Department of Radiation Oncology, Institute of

Oncology, University of Ljubljana, Ljubljana,

Slovenia

J. Corry

Division Radiation Oncology, Department of

Medicine, St. Vincent's Hospital/The University of

Melbourne, Melbourne, VIC, Australia evidence on the frequency, treatment, and outcome of RISHN.

Methods: Using PRISMA guidelines we conducted a systematic review of the literature published from 2000 to 2020 .

Results: Our review includes data of 560 patients from 64 articles. The total frequency of RISHNs among the reviewed series was $0.15 \%$. The most frequent location of the primary tumor treated by RT was the nasopharynx. The mean RT dose used was 62 Gy, mean latency interval between irradiation and occurrence of RISHN was 11.1 years, and the most common RISHN location was the sinonasal region.

A. Eisbruch

Department of Radiation Oncology, University of MI Hospitals-Michigan Medicine, Ann Arbor, MI, USA

J. J. Beitler

Departments of Radiation Oncology,

Otolaryngology and Medical Oncology, Emory

University School of Medicine, Atlanta, GA, USA

S. Nuyts

Department of Oncology, Radiation-Oncology, KU Leuven, University of Leuven, University Hospitals Leuven, Leuven, Belgium

R. Smee

Department of Radiation Oncology, The Prince of Wales Cancer Centre, Sydney, NSW, Australia

J. A. Langendijk

Department of Radiation Oncology, University

Medical Center Groningen, University of

Groningen, Groningen, The Netherlands 
Osteosarcoma was the principal histology, followed by fibrosarcoma. Surgery was the most frequently applied treatment modality. Of all patients with RISHN, $40.7 \%$ died of this disease after a mean interval of 13.9 months.

Conclusions: Notwithstanding the increased use of RT, the number of reported RISHNs has not increased substantially during the past two decades. Surgery with wide margins forms the best therapeutic option for these cases, but the outcome remains poor.

Keywords: Head and neck; Radiation-induced; Radiotherapy; Sarcoma; Surgical treatment

\section{Key Summary Points}

Radiation-induced sarcomas of the head and neck (RISHN) are a rare but lethal complication of radiotherapy.

The total frequency among the reviewed series was $0.15 \%$.

The mean latency interval between irradiation and occurrence of RISHN was 11.1 years and the most common RISHN location was the sinonasal region.

Osteosarcoma was the principal histology, followed by fibrosarcoma. Surgery was the most frequently applied treatment modality.
W. M. Mendenhall

Department of Radiation Oncology, University of

Florida College of Medicine, Gainesville, FL, USA

C. Piazza

Department of Otorhinolaryngology, Maxillofacial and Thyroid Surgery, Fondazione IRCCS Istituto Nazionale dei Tumori, Milan, Italy

A. Rinaldo

University of Udine School of Medicine, Udine, Italy

A. Ferlito

Coordinator of the International Head and Neck

Scientific Group, Padua, Italy
Despite the increased use of radiotherapy, RISHNs have not increased substantially during the past two decades. Surgery forms the best therapeutic option, but the outcome remains poor.

\section{DIGITAL FEATURES}

This article is published with digital features, including a summary slide, to facilitate understanding of the article. To view digital features for this article go to https://doi.org/10.6084/ m9.figshare.13143554.

\section{INTRODUCTION}

Radiation-induced sarcomas of the head and neck (RISHNs) pose a challenging entity in head and neck (HN) oncology. This tumor appears in irradiated tissues of the $\mathrm{HN}$ without any subsite predilection [1]. The median latency after radiotherapy (RT) is reported to be $10-12$ years [2]. The clinical features of RISHNs can be similar to other more common RT complications, like radionecrosis, which makes their diagnosis difficult in early stages, but sometimes symptoms are related to the region where the tumor appears: diplopia, neck mass, jaw numbness, or asymmetry in the $\mathrm{HN}$ region [3, 4]. The diagnostic criteria originally proposed by Cahan and Woodard [5] and modified by Murray et al. [6] are still frequently used and include (1) the tumor arises in a field that has been previously irradiated, (2) there is evidence that the first tumor differs histologically from the subsequent one, (3) there was no evidence of the new tumor at the time of RT, and (4) the new tumor developed after a latency period following RT.

RT has become one of the cornerstones in the treatment of $\mathrm{HN}$ cancer, paralleling an increase in long-term patient survival [7]. RISHNs are rare tumors, but the population growth, increased access to and use of RT, the increasing survival numbers, and advances in diagnostics have in turn been accompanied by an obvious increase in the frequency of RISHNs. In the study by Wei et al., the incidence of 
RISHN increased from $0.06 \%$ to $0.17 \%$ from 1960 to 2010 at their institution [8].

The most common histologic subtypes are osteosarcoma, undifferentiated pleomorphic sarcoma, and fibrosarcoma [9]. They do not show any subsite predilection and can arise in any irradiated tissue of mesenchymal origin within the $\mathrm{HN}$, with most of these tumors being of high grade [6].

Management of RISHNs remains controversial and all treatment modalities have been applied: surgery and chemotherapy, but also re-irradiation and a variety of combination of these modalities [8]. The overall prognosis is still poor with a 5-year overall survival rate varying between $24.2 \%$ and $38.2 \%[4,10-12]$.

The main objective of this systematic review was to determine the existing evidence on the frequency, treatment, and outcome of RISHN.

\section{METHODS}

The Preferred Reporting Items for Systematic Review and Meta-Analyses (PRISMA) method was used to analyze the current literature [13]. The search strategy aimed to include articles concerning the development of RISHNs in patients treated with RT. A PubMed search updated to July 24, 2020 was performed for publications in English between 2000 and 2020 using the following search criteria in the title or abstract: "head and neck" coupled with "radiation induced sarcomas", "radiation associated sarcomas", and "radiation induced malignancy". The search results were reviewed for potentially eligible studies. When there was any information in the abstract about the study addressing RISHNs, the full text article was searched. All review articles were also screened to identify reports on these patients. References from any full text articles were cross-checked to ensure inclusion of all relevant publications (Fig. 1). Studies were selected if they met the

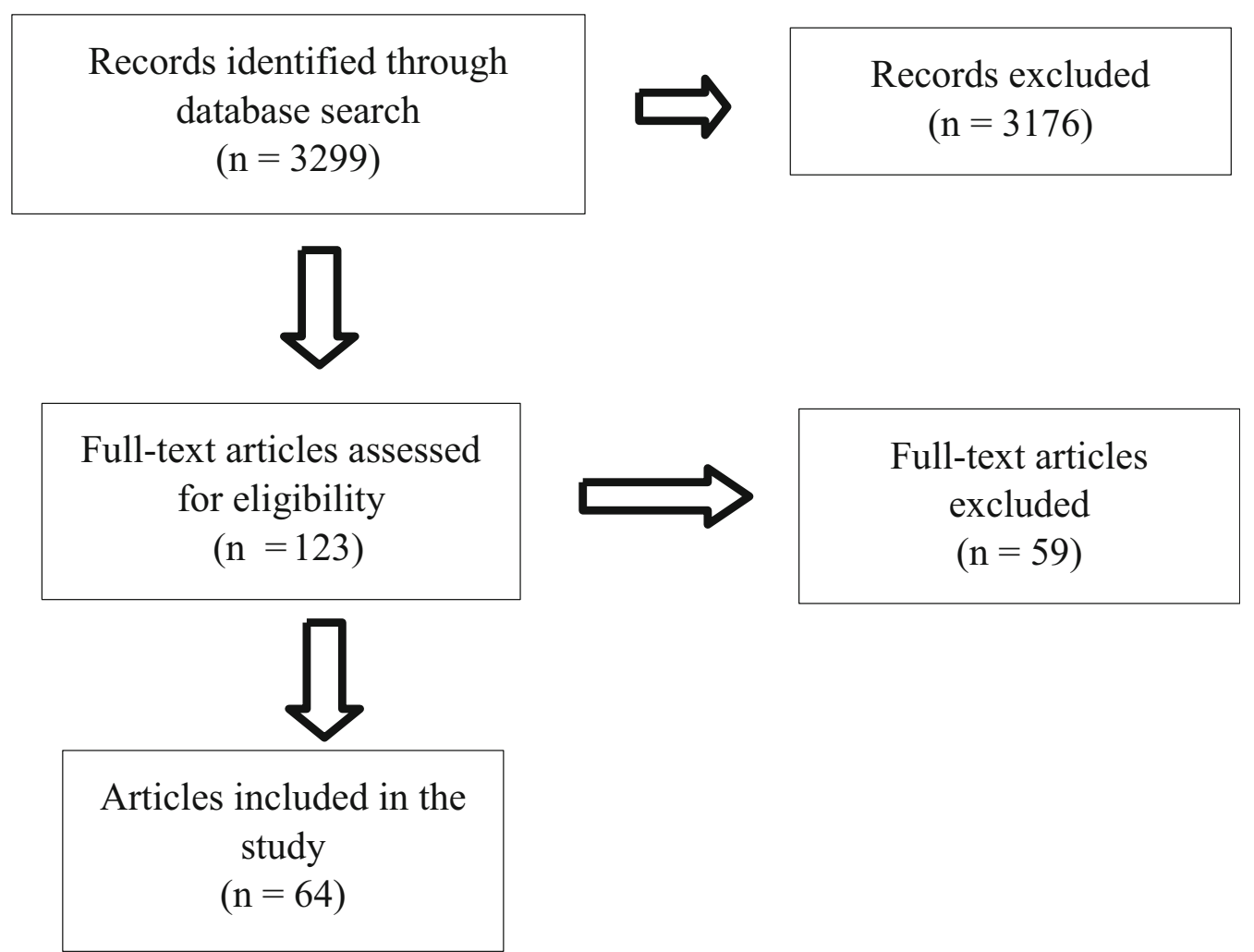

Fig. 1 Flowchart showing the study selection process for our systematic review 
following inclusion criteria: (a) patients treated with RT to their primary tumor, (b) radiationinduced sarcoma developed in the HN area, and (c) histological confirmation of the sarcoma has been obtained. Studies in which the RISHNs were analyzed together with non-HN radiationinduced sarcomas were excluded.

The statistical analysis was performed with SPSS statistical software (IBM SPSS 19.0 Statistical Software package). The Spearman's rho correlation coefficient was used for comparison between the age of the patients and the latency period to development of the sarcoma. In addition, differences between mean latency times by age group were analyzed using the analysis of variance (ANOVA) test. $P$ values of 0.05 or less were considered statistically significant.

This article is based on previously conducted studies and does not contain any studies with human participants or animals performed by any of the authors.

\section{RESULTS}

Our search criteria identified 3299 papers and, after removal of duplicates and those that did not meet our inclusion criteria, 64 were selected for data review as summarized in Table 1 $[1,3,4,8,10-12,14-70]$. Most papers were excluded because they involved radiation-induced sarcomas outside the HN area. Our review includes 560 patients with 561 RISHNs (one patient had two simultaneous tumors) from 64 articles during a period of 20 years (2000-2020). Some of the parameters addressed were not available in all studies. There were 363 men and 179 women (male-to-female ratio, 2:1). The most frequently reported location of the primarily treated tumor was the nasopharynx (368 cases, or $65.7 \%)$, followed by the sinonasal region (21 cases, or $3.7 \%$ ), central nervous system (19 cases, or $3.4 \%)$, eye (14 cases, or $2.5 \%)$, and larynx (13 cases, or $2.3 \%)$. The mean RT dose prescribed to the primary tumor was $62 \mathrm{~Gy}$ (range 36-101). RISHNs most frequently appeared in the sinonasal region $(33.7 \%)$, followed by the mandible and the neck $(15.9 \%$ and $13.4 \%$, respectively). The most common histologies were osteosarcoma (35.5\%) and fibrosarcoma (23\%). The median age at diagnosis of RISHN was 52 years (interquartile range 21.5) and the mean latency between the initial RT treatment and the diagnosis of RISHN was 11.1 years (range $1.3-38$ ). The mean age at the treatment of the primary tumor was 43.1 years (range $2-81$ ), but still only $37.5 \%$ of the patients had a mean age of less than 40 years. Most of the patients $(62.5 \%)$ in our review had a mean age of 40 years or older when they were treated for the primary tumor with RT. This leads us to think that RISHNs are less frequent in young patients who are treated with RT. In order to investigate if age at the time of the primary RT treatment is related to latency time, we analyzed these two groups separately, i.e., patients under 40 years old and patients older than 40 years. In the group of patients under 40 years of age, the mean age was 26 years (range 2-38.6) with a mean latency until diagnosis of the sarcoma of 14.1 years (range 2.3-38). On the other hand, in the group of patients aged older than 40 years, the mean age was 55.1 years (range 40-81) and a mean latency until appearance of the sarcoma of 9.6 years (range 1.3-22).

The Spearman's rho correlation coefficient was used for comparison between these two groups. The result was that there is an inverse correlation $(\rho=-0.423)$ between age at the primary RT treatment and latency time, and this result was statistically significant $(P=0.001)$. So, the older the patient, the shorter the latency period. Differences between mean latency times in these two age groups were analyzed using the ANOVA test, and the result was that the latency time is greater in patients under 40 years of age and the difference is statistically significant $(P=0.01)$. Therefore, older patients treated with RT develop the sarcoma sooner after treatment than younger patients.

The most frequently used treatment modality was surgery (45.1\%), and less commonly multimodal treatment (24.1\%). Chemotherapy or RT alone were used less often $(8.9 \%$ and $5.2 \%$, respectively) and these modalities were mostly applied as palliative treatment. A total number of 228 patients died of the RISHN $(40.7 \%)$ after a mean time of 13.9 months 


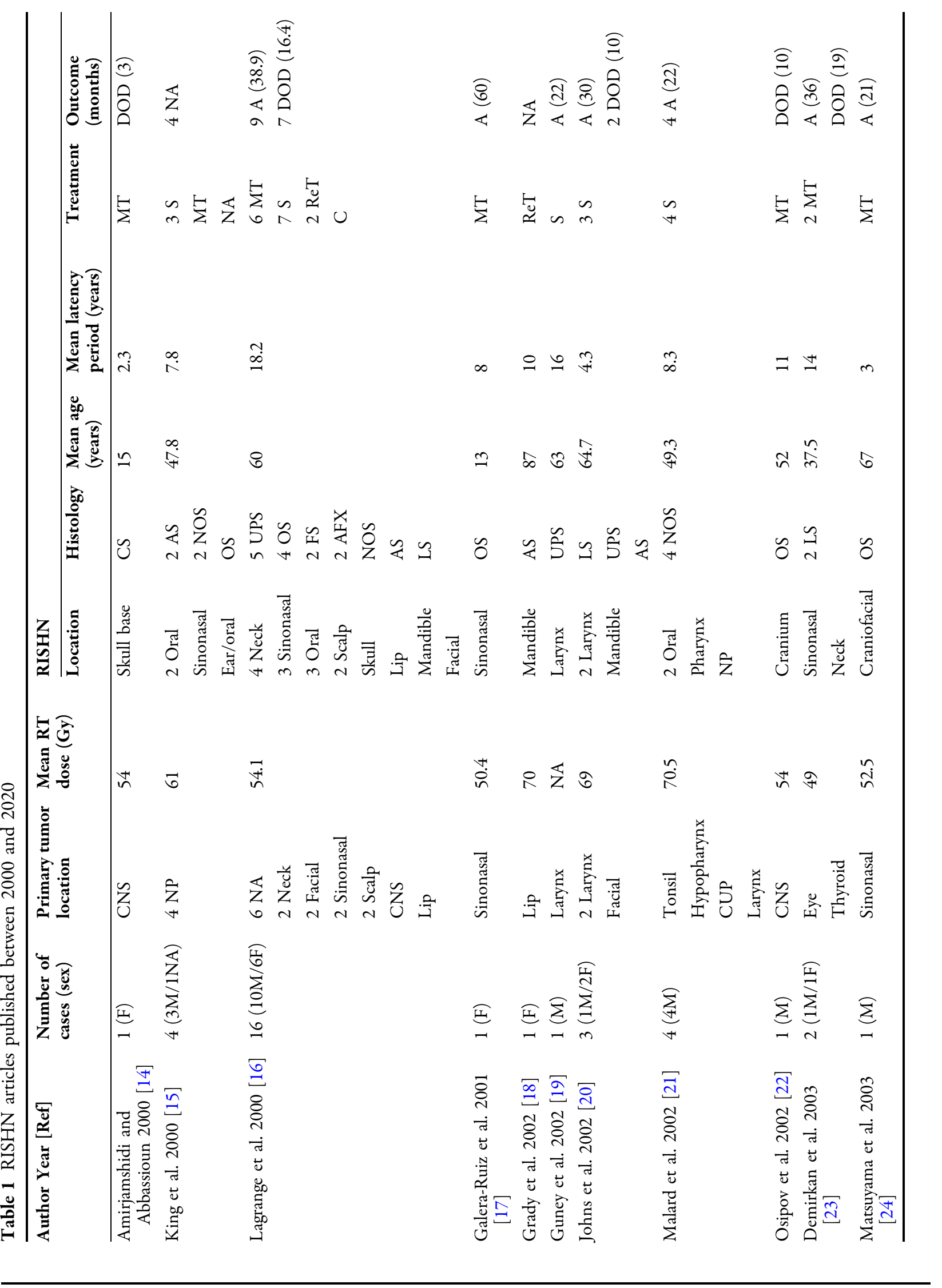




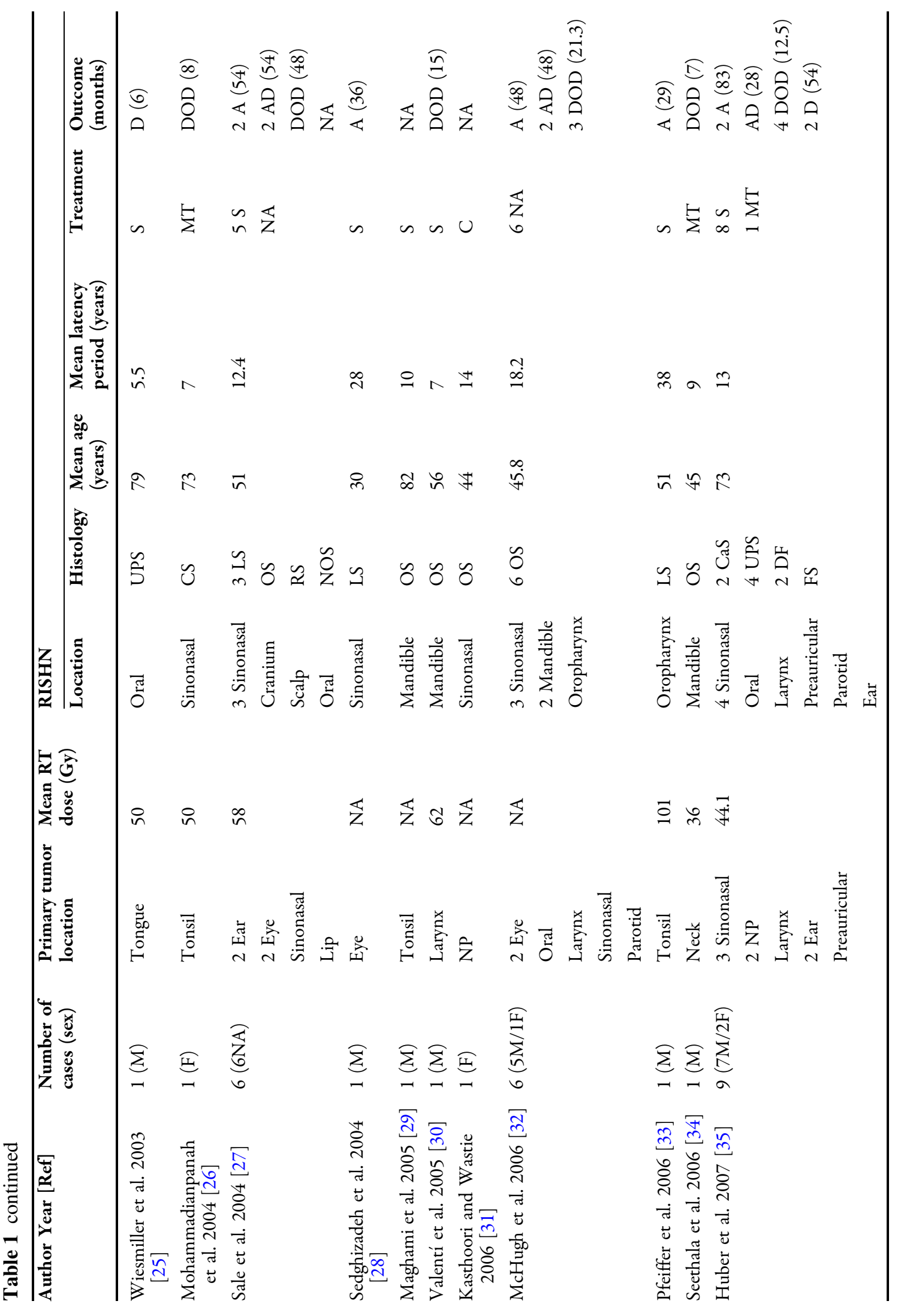




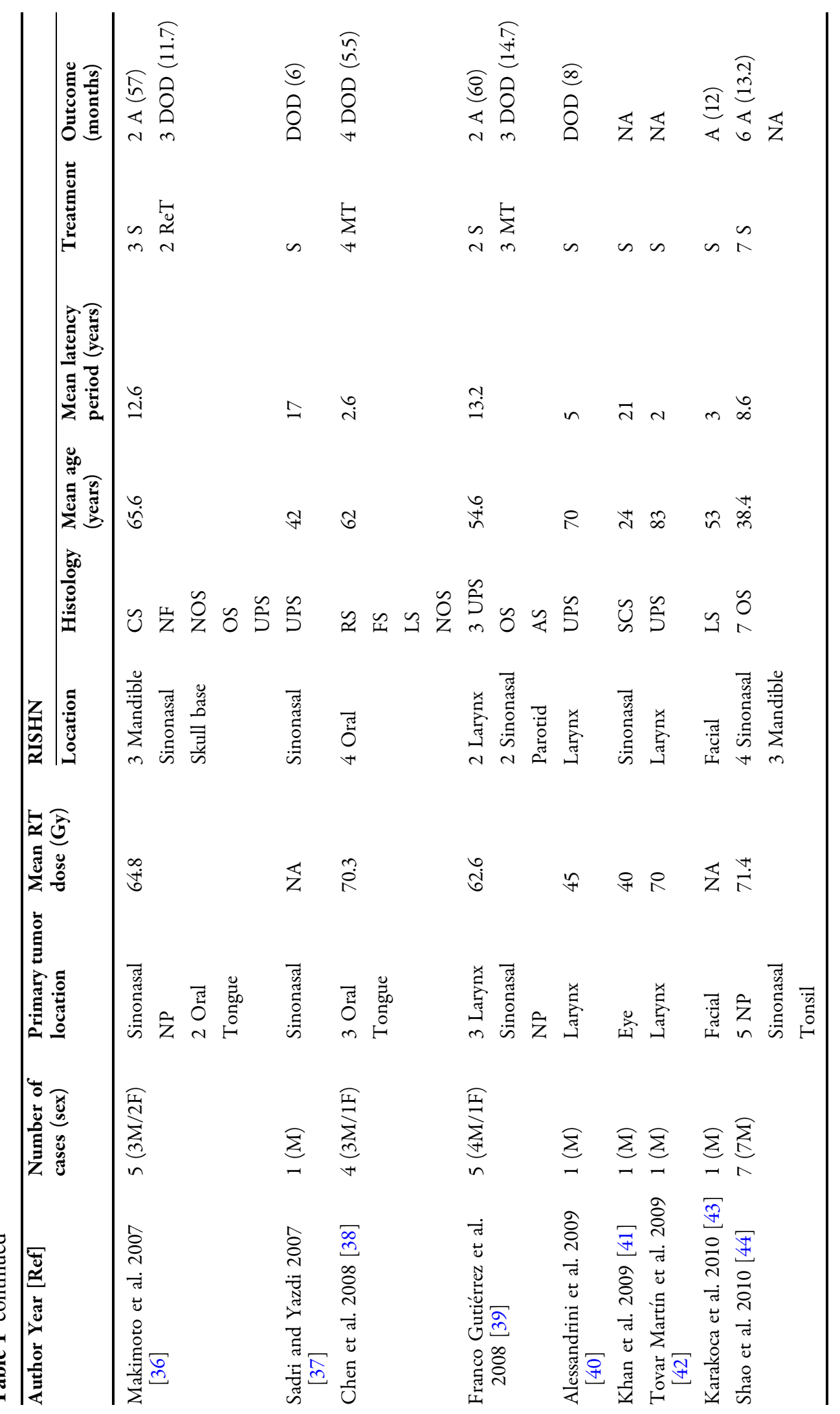




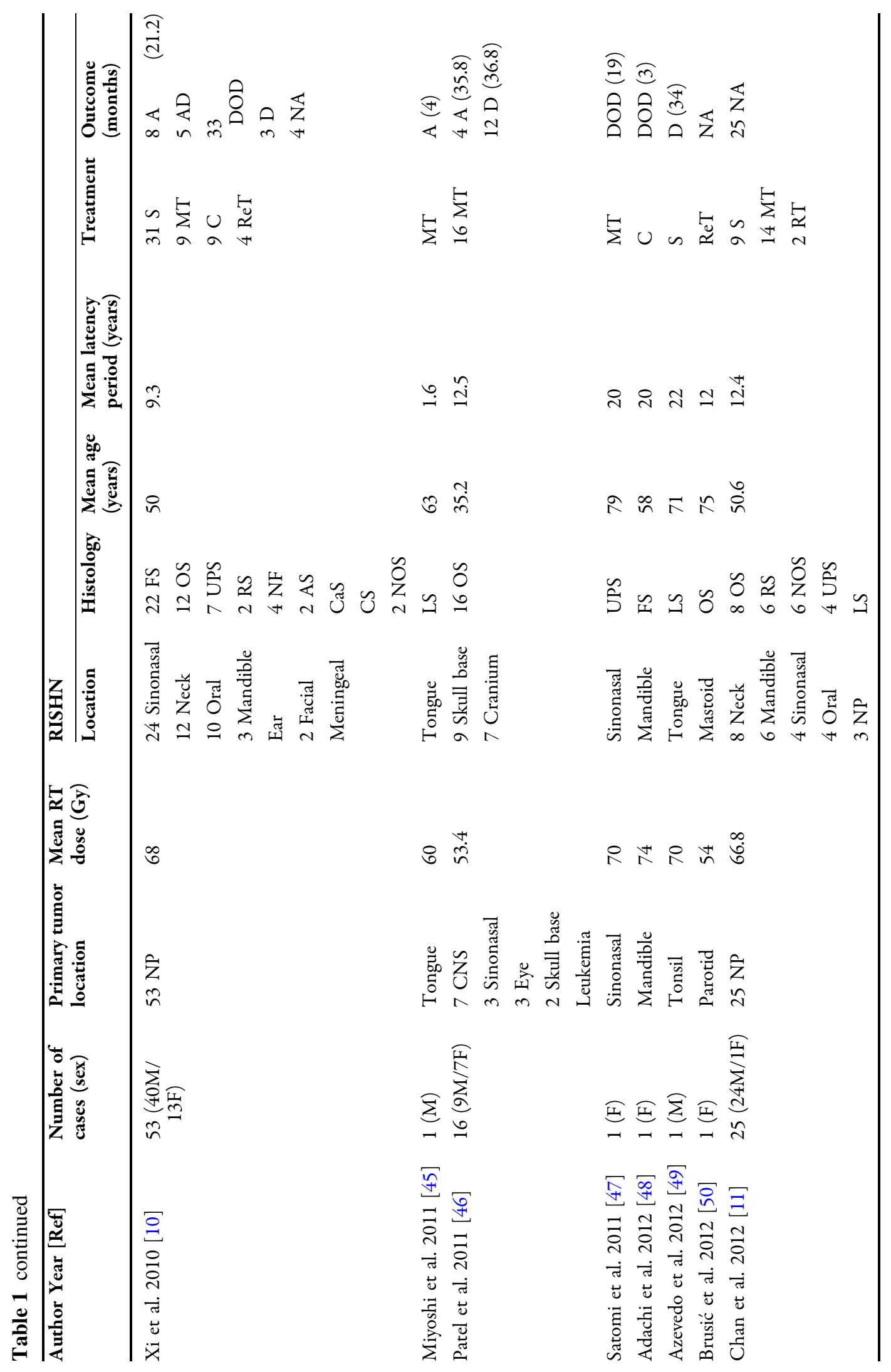




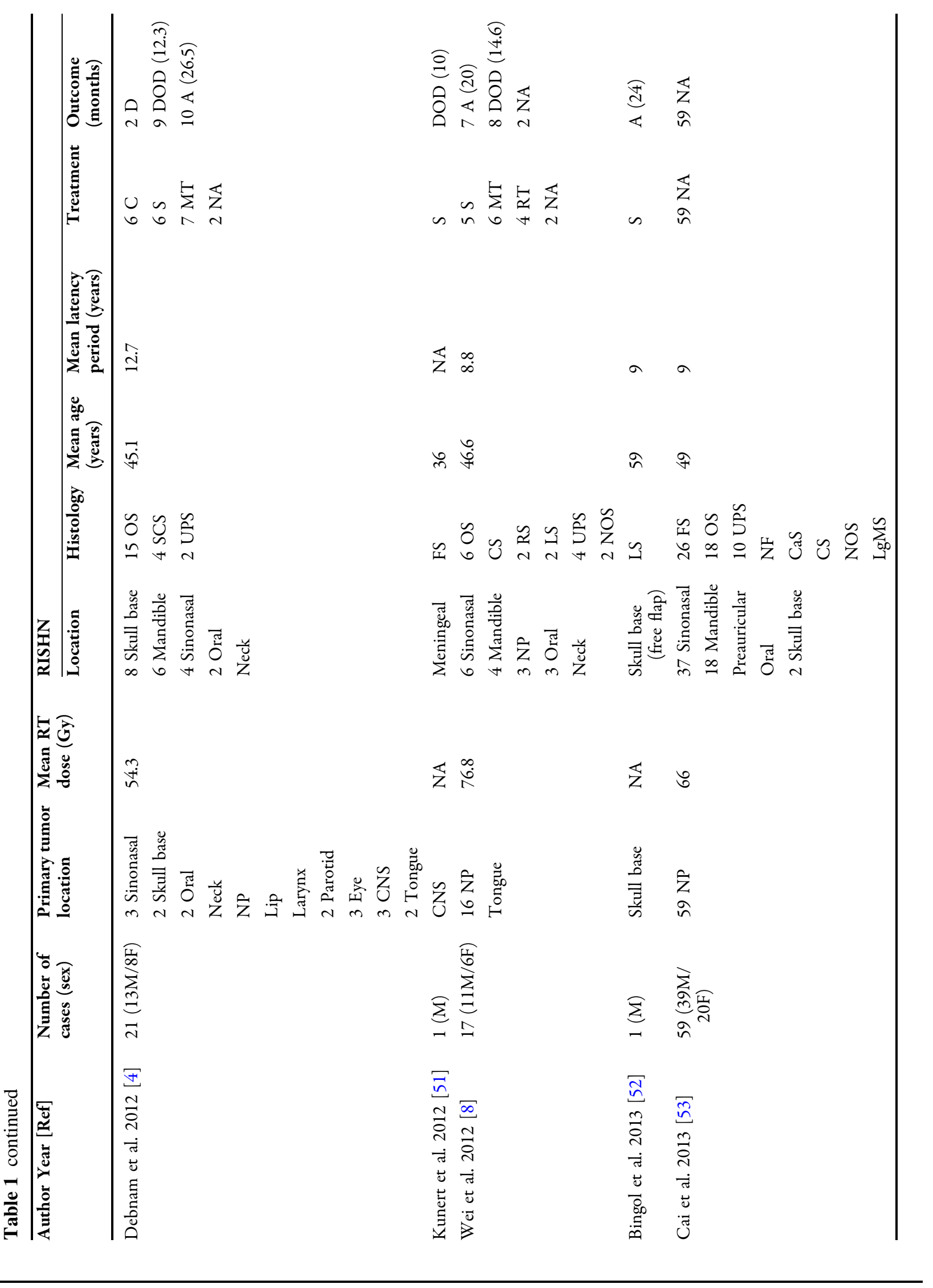




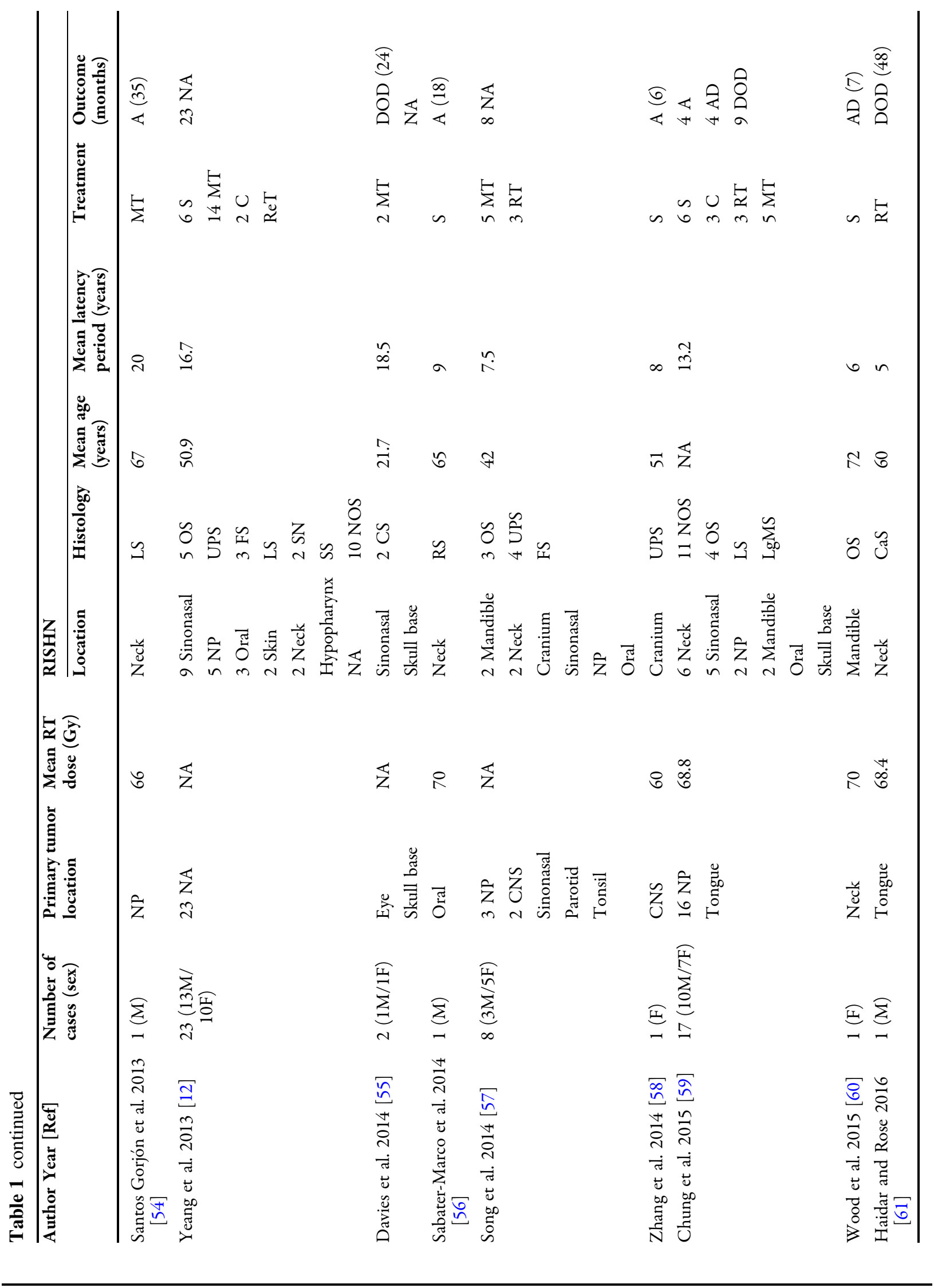




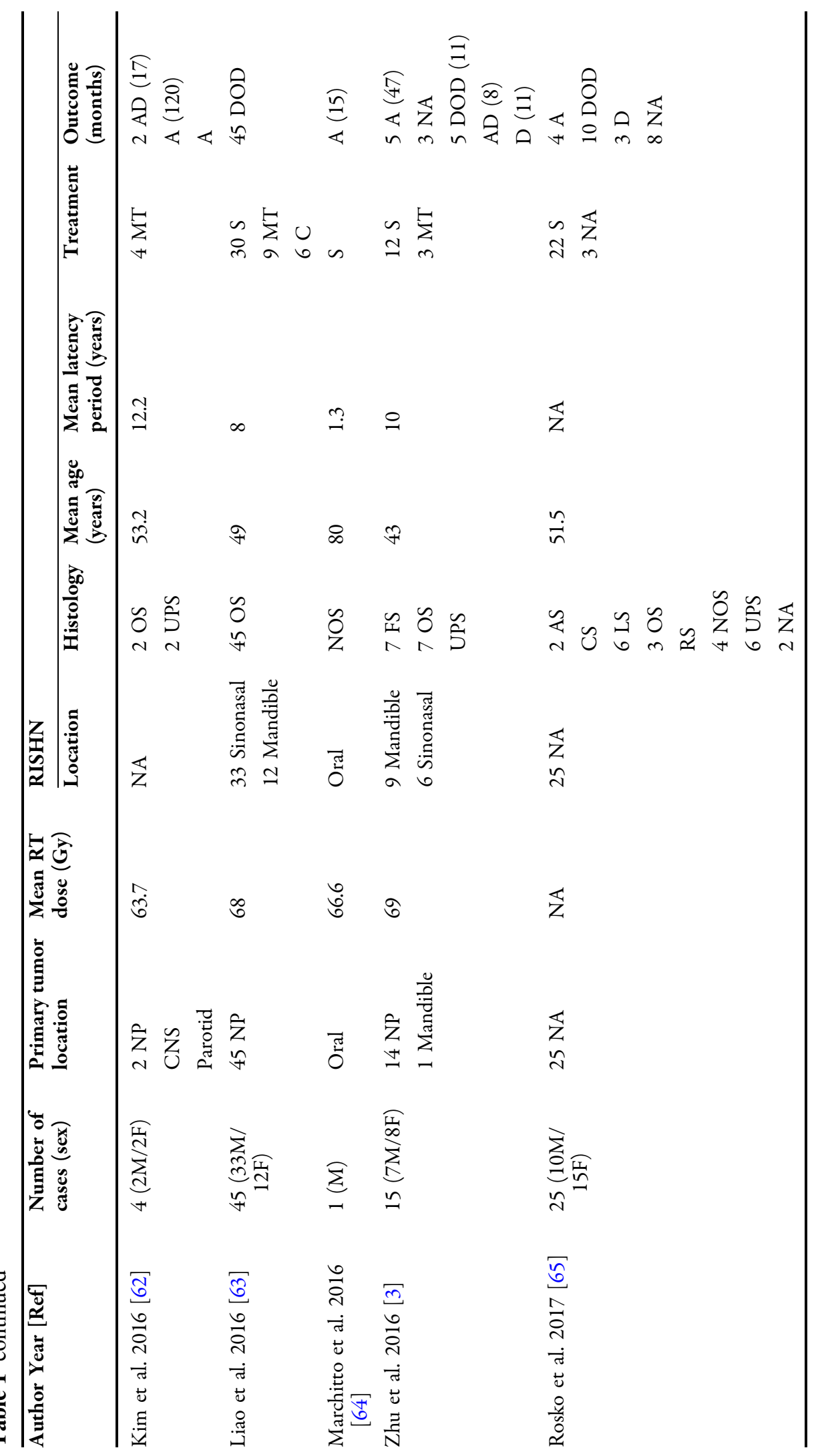




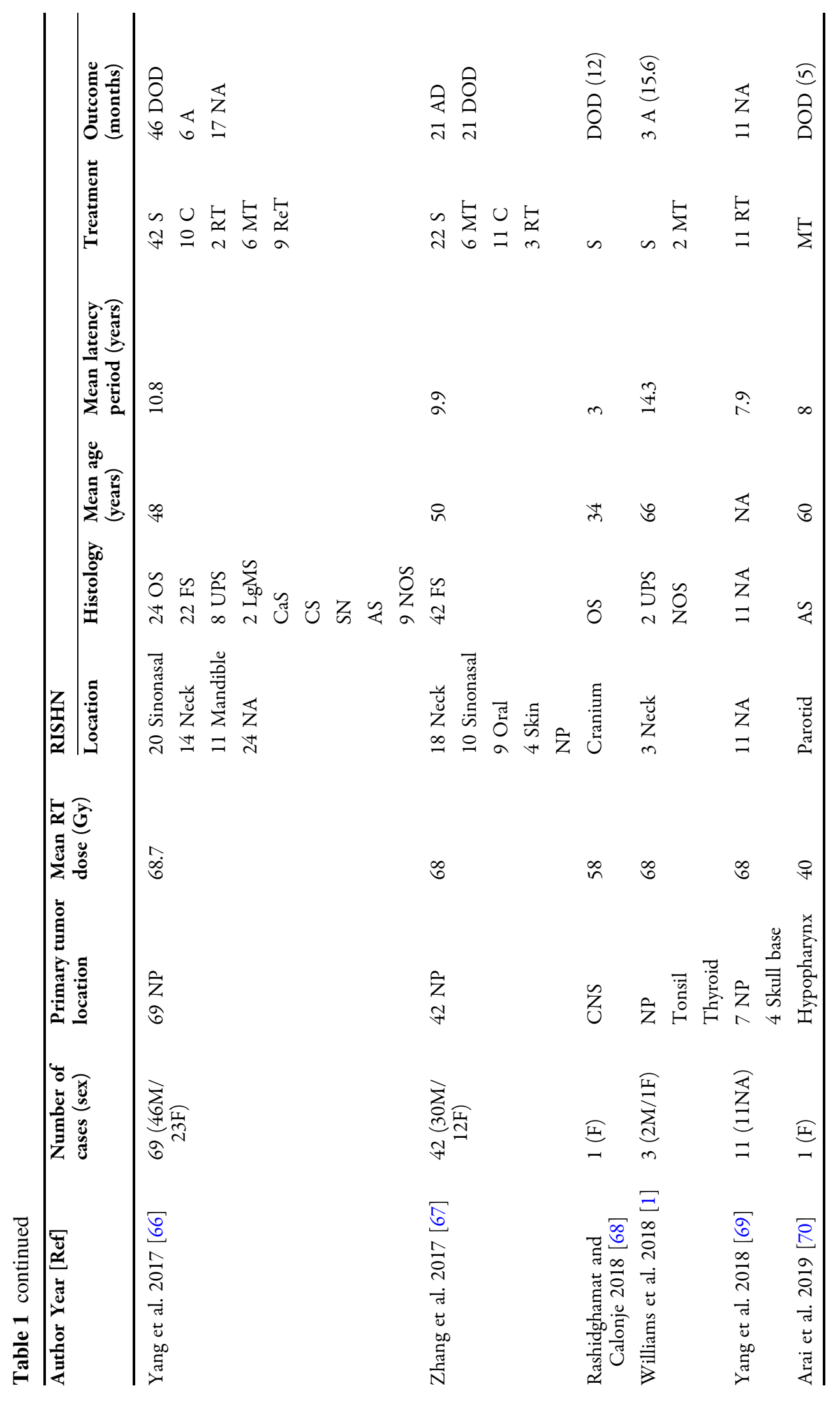




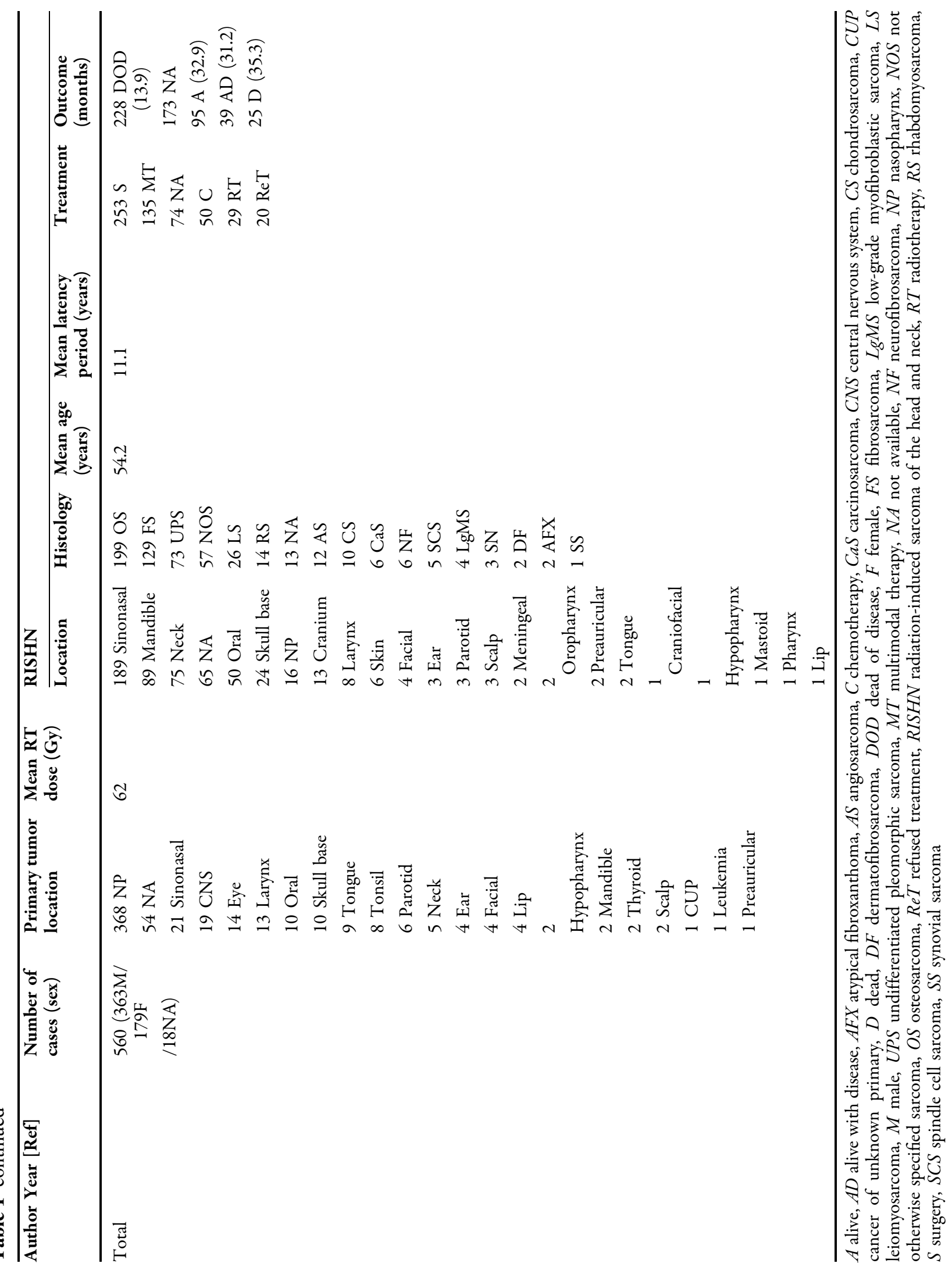


Table 2 Frequency of RISHNs in the published series

\begin{tabular}{|c|c|c|c|}
\hline Author Year [Ref] & $N$ patients & $\begin{array}{l}N \text { of } \\
\text { RISHN }\end{array}$ & $\begin{array}{l}\text { Frequency } \\
(\%)\end{array}$ \\
\hline $\begin{array}{l}\text { Makimoto et al. } \\
2007 \text { [36] }\end{array}$ & 4194 & 5 & 0.12 \\
\hline Xi et al. 2010 [10] & 39,118 & 53 & 0.13 \\
\hline $\begin{array}{l}\text { Kunert et al. } 2012 \\
\text { [51] }\end{array}$ & 433 & 1 & 0.2 \\
\hline Wei et al. 2012 [8] & 16,634 & 17 & 0.1 \\
\hline $\begin{array}{l}\text { Cai et al. } 2013 \\
\text { [53] }\end{array}$ & 22,386 & 59 & 0.26 \\
\hline $\begin{array}{l}\text { Liao et al. } 2016 \\
\quad[63]\end{array}$ & 53,760 & 45 & 0.08 \\
\hline $\begin{array}{l}\text { Yang et al. } 2017 \\
{[66]}\end{array}$ & 27,714 & 69 & 0.24 \\
\hline $\begin{array}{l}\text { Williams et al. } \\
2018 \text { [1] }\end{array}$ & 3906 & 3 & 0.07 \\
\hline Total & 168,115 & 252 & 0.15 \\
\hline
\end{tabular}

(range 3-48) after the diagnosis of RISHN. There was a large number of patients for whom survival data were not available (173 cases, $30.9 \%$ ). Ninety-five patients $(17 \%)$ were alive without known disease with a mean survival time of 32.9 months (range 4-120). For patients alive with disease the mean survival was 31.2 months (range 7-54). In total, $4.5 \%$ of the patients died from intercurrent disease. In order to know if the results of the treatment of these patients have varied over the years because of the advances that have been experienced both in surgery and in oncological treatments, we divided the reviewed articles into two groups according to the year when they were published: 2000-2010 and 2011-2020. In the 2000-2010 group, the patients died of disease after a mean time period of 13.5 months (range 3-48), and the mean follow-up time for those alive with no evidence of disease was 36.3 months (range 12-83), and for those alive with disease it was 46.4 months (range 28-54). In the 2011-2020 group, the patients died of disease after a mean survival time period of
13.9 months (range 3-48), the mean follow-up time for those alive with no evidence of disease was 29.2 months (range 4-120), and for those alive with disease it was 12.2 months (range 7-17). Therefore, it seems that the mean life expectancy for those patients dying of RISHN has remained practically the same in the articles published during the past two decades. The follow-up times for the patients alive were longer in the earlier group and thus no conclusions can be drawn regarding their results.

The frequency of reported RISHNs in the published series is given in Table 2. In total, there were 252 RISHNs among 168,115 patients who had been treated with RT, with a mean frequency of $0.15 \%$. It should be noted that this frequency in the present systematic review is reported according to the date of publication of the reviewed articles, i.e., between 2000 and 2020. However, the included patient series in these reviews cover much longer period, specifically from 1964 to 2015 .

\section{DISCUSSION}

RISHNs remain a rare late complication of RT, and typically occur between 10 and 12 years after RT [2]. The effectiveness of RT for treatment of cancers and its increasingly widespread use have led to a parallel surge in adverse effects arising from it. This rise may be also due to the higher long-term survival rate generally observed in HN cancers (owing to early diagnosis, improved oncological and surgical techniques, and the use of systemic therapy), and the use of higher RT doses $[3,8]$. In the present review, we found a frequency of $0.15 \%$ for RISHNs in the series published during the two past decades. The significance of this finding remains questionable, as only eight series with 252 patients were included, although the whole cohort having received RT in the included reports was rather representative with 168,115 patients.

The exact etiology of RISHNs remains unknown, but radiation likely induces their development by causing damage to DNA within the cells [3]. There is no safe threshold in terms of RT dose, below which there is no risk of 
causing a second tumor [2]. The results of some studies indicated that the risk of developing RISHN increases with accumulated radiation dosage [71]. More specifically, in one study a total dose higher than $30 \mathrm{~Gy}$ increased the risk of developing RISHN [72]. As we included only patients treated with curative intent, the mean RT dose received for treating the primary tumor was $62 \mathrm{~Gy}$ (range 36-101) and thus these patients were considered at risk for developing RISHN. We are aware that sarcomas sometimes appear in areas of medium dose within the primary RT field, so the dose received in the primary tumor may not be as important as the dose delivered in the area where the sarcoma appears. Unfortunately, these data are usually not available in the published articles, and instead only the mean dose is reported.

The age range of patients with RISHNs varied among studies, but usually occurs between the 6 th and 7 th decade of life $[1,6,8]$. We found that the median age at diagnosis was 52 years (interquartile range 21.5), which is in line with what has been published previously.

The mean latency period in our review was 11.1 years, but with a wide range (1.3-38 years), possibly because there are many single cases published. In the past, the latency time factor was used to differentiate radiation-induced sarcomas from de novo sarcomas, but now most studies do not take that time period into consideration and those that occur with short latency periods are included as radiation-induced sarcomas, since they are impossible to differentiate [12]. There are studies demonstrating a shorter latency period (between 7.7 and 9.3 years) than the one reported in our review (11.1 years), but the mean age in these series was almost 50 years. This is in accordance with the latency period of 9.6 years for the patients over the age of 40 years in the present review $[8,10]$.

The location of the RISHN depends essentially on the location of the primary tumor. Nasopharyngeal cancer irradiation was typical in the present review and has been reported earlier [66] and consequently the most common site of RISHN being the paranasal sinuses. Sinonasal tract, central nervous system, eye, and larynx were frequent primary tumor sites as well among the present studies.

With regard to the different histological RISHN subtypes that can be observed, the following histologies have been described: fibrosarcoma, osteosarcoma, undifferentiated pleomorphic sarcoma, chondrosarcoma, angiosarcoma, leiomyosarcoma, rhabdomyosarcoma, spindle cell sarcoma, and others [3]. Cai et al. [53] found that the most common histologies were fibrosarcoma (44.1\%) and osteosarcoma (30.5\%). Zhu et al. [3] found osteosarcoma to be the most common histology (34.1\%), followed by fibrosarcoma (19.2\%) and undifferentiated pleomorphic sarcoma (15.8\%). In the study by Thiagarajan and Gopalakrishna Iyer [9], undifferentiated pleomorphic sarcoma was the most frequent histology. In our study, the most frequently encountered histologic types were osteosarcoma (35.5\%) and fibrosarcoma $(23 \%)$, which is in line with some of the previously published studies. Less common were undifferentiated pleomorphic sarcoma (13\%) and sarcomas not otherwise specified (10.2\%).

Treatment of RISHN varied widely between the studies. In our review, almost half of the patients received surgical treatment $(45.1 \%)$ when the lesion was resectable. Other modalities, like RT or chemotherapy alone or multimodality treatment, were used less commonly. As RISHNs are rare tumors, with varying histologies at different locations and the available knowledge being based on retrospective studies, it is difficult to define clear recommendations for their treatment. As RISHNs most frequently occur in previously irradiated areas that received a high dose, surgery remains the preferred treatment modality in case RISHN is considered resectable. Adequate surgical margins are difficult to achieve, and this is even more difficult when neighboring vital structures and the previous RT-induced fibrous transformation of tissues with impaired blood flow further complicate surgery and increase complication rates [73]. In unresectable cases, definitive radiotherapy alone or combined with systemic treatment may be considered but is generally associated with a high risk of severe radiation-induced side effects and, furthermore, 
there have been no advances in terms of effective systemic therapies. According to some authors, chemotherapy will be less effective in radiation-induced sarcomas compared with de novo sarcomas because of fibrotic changes in the previously irradiated field and, consequently, impaired vascularity thus impeding chemotherapeutic agents from reaching adequate concentrations in the target area [16], but the evidence for this is lacking.

Cha et al. [73] reviewed the results obtained by surgical resection of RISHNs and found that the 1-year, 3-year, and 5-year overall survival rates were $78 \%, 58 \%$, and $41 \%$, respectively, with a median survival of 48 months. The 3 -year overall survival rate reported by $\mathrm{Xi}$ et al. [10] was $32.4 \%$ and the 5-year overall survival rate reported by Chan et al. [11] was $24.2 \%$. For Yeang et al. [12] the 2-year and 5-year overall survival rates were $57.3 \%$ and $38.2 \%$, respectively. Unfortunately, overall survival data were not available in most of the studies in this review, given the large number of included case reports.

\section{CONCLUSION}

Our review represents the most comprehensive systematic analysis of RISHNs to date, collecting data from 560 patients. Most of the included studies were case reports or only comprised a few cases. We herein emphasize that RISHNs are a rare but lethal complication of RT. The frequency has remained rather stable. Surgery with free margins remains the treatment option of choice for RISHNs. However, given the location of the tumor, this may be difficult to achieve in some cases.

\section{ACKNOWLEDGEMENTS}

Funding. No funding or sponsorship was received for this study or publication of this article.

Authorship. All named authors meet the International Committee of Medical Journal
Editors (ICMJE) criteria for authorship for this article, take responsibility for the integrity of the work as a whole, and have given their approval for this version to be published.

Disclosures. Andrés Coca-Pelaz, Antti A. Mäkitie, Primož Strojan, June Corry, Avraham Eisbruch, Jonathan J. Beitler, Sandra Nuyts, Robert Smee, Johannes A. Langendijk, William M. Mendenhall and Cesare Piazza have nothing to disclose. Alessandra Rinaldo and Alfio Ferlito are editorial board members of Advances in Therapy but have nothing else relevant to disclose.

Compliance with Ethics Guidelines. This article is based on previously conducted studies and does not contain any studies with human participants or animals performed by any of the authors.

Data Availability. Data sharing is not applicable to this article as no datasets were generated or analyzed during the current study.

Open Access. This article is licensed under a Creative Commons Attribution-NonCommercial 4.0 International License, which permits any non-commercial use, sharing, adaptation, distribution and reproduction in any medium or format, as long as you give appropriate credit to the original author(s) and the source, provide a link to the Creative Commons licence, and indicate if changes were made. The images or other third party material in this article are included in the article's Creative Commons licence, unless indicated otherwise in a credit line to the material. If material is not included in the article's Creative Commons licence and your intended use is not permitted by statutory regulation or exceeds the permitted use, you will need to obtain permission directly from the copyright holder. To view a copy of this licence, visit http://creativecommons.org/licenses/by$\mathrm{nc} / 4.0 /$. 


\section{REFERENCES}

1. Williams L, Tmanova L, Mydlarz WK, et al. Radiation-associated sarcoma of the neck: case series and systematic review. Ann Otol Rhinol Laryngol. 2018;127:735-40.

2. Giannini L, Incandela F, Fiore $M$, et al. Radiationinduced sarcoma of the head and neck: a review of the literature. Front Oncol. 2018;8:449.

3. Zhu W, Hu F, Zhao T, Wang C, Tao Q. Clinical characteristics of radiation-induced sarcoma of the head and neck: review of 15 cases and 323 cases in the literature. J Oral Maxillofac Surg. 2016;74: 283-91.

4. Debnam JM, Guha-Thakurta N, Mahfouz YMM, et al. Radiation-associated head and neck sarcomas: spectrum of imaging findings. Oral Oncol. 2012;48: 155-61.

5. Cahan WG, Woodard HQ. Sarcoma arising in irradiated bone; report of 11 cases. Cancer. 1948;1: 3-29.

6. Murray EM, Werner D, Greeff EA, Taylor DA. Postradiation sarcomas: 20 cases and a literature review. Int J Radiat Oncol Biol Phys. 1999;45: 951-61.

7. Bjerkehagen $\mathrm{B}$, Småstuen $\mathrm{MC}$, Hall KS, Skjeldal S, Smeland S, Fosså SD. Why do patients with radiation-induced sarcomas have a poor sarcoma-related survival? Br J Cancer. 2012;106:297-306.

8. Wei Z, Xie Y, Xu J, et al. Radiation-induced sarcoma of head and neck: 50 years of experience at a single institution in an endemic area of nasopharyngeal carcinoma in China. Med Oncol. 2012;29:670-6.

9. Thiagarajan A, Gopalakrishna Iyer N. Radiation-induced sarcomas of the head and neck. World J Clin Oncol. 2014;5:973-81.

10. Xi M, Liu M-Z, Wang H-X, et al. Radiation-induced sarcoma in patients with nasopharyngeal carcinoma: a single-institution study. Cancer. 2010;116: 5479-86.

11. Chan JYW, Wong STS, Lau GISK, Wei WI. Postradiation sarcoma after radiotherapy for nasopharyngeal carcinoma. Laryngoscope. 2012;122: 2695-9.

12. Yeang MS, Tay K, Ong WS, et al. Outcomes and prognostic factors of post-irradiation and de novo sarcomas of the head and neck: a histologically matched case-control study. Ann Surg Oncol. 2013;20:3066-75.
13. Shamseer L, Moher D, Clarke M, et al. Preferred reporting items for systematic review and metaanalysis protocols (PRISMA-P) 2015: elaboration and explanation. BMJ. 2015;350:g7647.

14. Amirjamshidi A, Abbassioun K. Radiation-induced tumors of the central nervous system occurring in childhood and adolescence. Childs Nerv Syst. 2000;16:390-7.

15. King AD, Ahuja AT, Teo P, Tse GMK, Kew J. Radiation induced sarcomas of the head and neck following radiotherapy for nasopharyngeal carcinoma. Clin Radiol. 2000;55:684-9.

16. Lagrange J-L, Ramaioli A, Chateau M-C, et al. Sarcoma after radiation therapy: retrospective multiinstitutional study of 80 histologically confirmed cases. Radiology. 2000;216:197-205.

17. Galera-Ruiz H, Sanchez-Calzado JA, Rios-Martin JJ, DeMingo-Fernandez EJ, Muñoz BF. Sinonasal radiation-associated osteosarcoma after combined therapy for rhabdomyosarcoma of the nose. Auris Nasus Larynx. 2001;28:261-4.

18. Grady AM, Krishnan V, Cohen L. Postirradiation angiosarcoma of the head and neck: report of a case. J Oral Maxillofac Surg. 2002;60:828-31.

19. Guney E, Yigitbasi OG, Balkanli S, Canoz OM. Postirradiation malignant fibrous histiocytoma of the larynx: a case report. Am J Otolaryngol. 2002;23:293-6.

20. Johns MM, Concus AP, Beals TF, Teknos TN. Earlyonset postirradiation sarcoma of the head and neck: report of three cases. Ear Nose Throat J. 2002;81: 402-6.

21. Malard O, Toquet C, Gayet-Delacroix M, Bordure $\mathrm{P}$, De Beauvillain MC, Bardet E. Radiation-induced cancers of the pharynx and larynx: a study of five clinical cases. Clin Otolaryngol Allied Sci. 2002;27: 68-74.

22. Osipov V, Ho K-C, Krouwer HG, Meyer G, Shidham VB. Post-radiation dedifferentiation of meningioma into osteosarcoma. BMC Cancer. 2002;2:34.

23. Demirkan F, Unal S, Cenetoğlu S, Cinel L. Radiation-induced leiomyosarcomas as second primary tumors in the head and neck region: report of 2 cases. J Oral Maxillofac Surg. 2003;61:259-63.

24. Matsuyama A, Yonemitsu N, Hayashida S, Watanabe $\mathrm{K}$, Sugihara $\mathrm{H}$, Inokuchi A. Case of postradiation osteosarcoma with a short latency period of 3 years. Pathol Int. 2003;53:46-50. 
25. Wiesmiller K, Barth TFE, Gronau S. Early radiationinduced malignant fibrous histiocytoma of the oral cavity. J Laryngol Otol. 2003;117:224-6.

26. Mohammadianpanah M, Gramizadeh B, Omidvari S, Mosalaei A. Radiation-induced chondrosarcoma of the maxilla 7-year after combined chemoradiation for tonsillar lymphoma. J Postgrad Med. 2004;50:200-1.

27. Sale KA, Wallace DI, Girod DA, Tsue TT. Radiationinduced malignancy of the head and neck. Otolaryngol Head Neck Surg. 2004;131:643-5.

28. Sedghizadeh PP, Angiero F, Allen CM, Kalmar JR, Rawal Y, Albright EA. Post-irradiation leiomyosarcoma of the maxilla: report of a case in a patient with prior radiation treatment for retinoblastoma. Oral Surg Oral Med Oral Pathol Oral Radiol Endod. 2004;97:726-31.

29. Maghami EG, St-John M, Bhuta S, Abemayor E. Postirradiation sarcoma: a case report and current review. Am J Otolaryngol. 2005;26:71-4.

30. Valentí V, López-Pousa A, Gonzalez Y, Farré N. Radiation-induced mandibular osteogenic sarcoma: report of a case and review of the literature. J Craniofac Surg. 2005;16:452-6.

31. Kasthoori JJ, Wastie ML. Radiation-induced osteosarcoma of the maxilla. Singap Med J. 2006;47:907-9.

32. McHugh JB, Thomas DG, Herman JM, et al. Primary versus radiation-associated craniofacial osteosarcoma: biologic and clinicopathologic comparisons. Cancer. 2006;107:554-62.

33. Pfeiffer J, Boedeker CC, Ridder GJ, Maier W, Kayser G. Radiation-induced leiomyosarcoma of the oropharynx. Diagn Pathol. 2006;1:22.

34. Seethala RR, Sturgis EM, Raymond AK, Deavers MT. Postirradiation osteosarcoma of the mandible with heterologous differentiation. Arch Pathol Lab Med. 2006;130:385-8.

35. Huber GF, Matthews TW, Dort JC. Radiation-induced soft tissue sarcomas of the head and neck. J Otolaryngol. 2007;36:93-7.

36. Makimoto $Y$, Yamamoto S, Takano H, et al. Imaging findings of radiation-induced sarcoma of the head and neck. Br J Radiol. 2007;80:790-7.

37. Sadri D, Yazdi I. Postradiation malignant fibrous histiocytoma of the maxillary sinus. Arch Iran Med. 2007;10:393-6.

38. Chen Y-W, Tu H-F, Wu T-H, et al. Sarcomas and sarcomatoid tumor after radiotherapy of oral squamous cell carcinoma: analysis of 4 cases. Oral Surg Oral Med Oral Pathol Oral Radiol Endod. 2008;105:65-71.

39. Franco Gutiérrez V, Llorente Pendás JL, Coca Pelaz A, Cabanillas Farpón R, Suárez NC. Radiation-induced sarcomas of the head and neck. J Craniofac Surg. 2008;19:1287-91.

40. Alessandrini M, De Padova A, Saccoccio A, et al. Post-irradiation malignant fibrous histiocytoma of the larynx: a case report with an unusual metastatic spread pattern. Auris Nasus Larynx. 2009;36: 609-13.

41. Khan M, Chandramala R, Sharma R, Vijayalakshmi KR. Radiation-induced spindle cell sarcoma: a rare case report. Indian J Dent Res. 2009;20:380-4.

42. Tovar Martín MI, Martínez Carrillo M, Chamorro Santos CE. Early radiation-induced laryngeal malignant fibrous histiocytoma (MFH). Clin Transl Oncol. 2009;11:701-3.

43. Karakoca S, Aydin C, Yilmaz H, Bal BT. Radiationinduced leiomyosarcoma of the maxillofacial region: facial reconstruction with implant-retained prosthesis. J Craniofac Surg. 2010;21:262-6.

44. Shao Z, He Y, Wang L, Hu H, Shi H. Computed tomography findings in radiation-induced osteosarcoma of the jaws. Oral Surg Oral Med Oral Pathol Oral Radiol Endod. 2010;109:e88-94.

45. Miyoshi T, Takebayashi S, Suzuki C, et al. Earlyonset postirradiation sarcoma of the tongue after pseudotumor phase. ORL J Otorhinolaryngol Relat Spec. 2011;73:201-5.

46. Patel AJ, Rao VY, Fox BD, et al. Radiation-induced osteosarcomas of the calvarium and skull base. Cancer. 2011;117:2120-6.

47. Satomi T, Watanabe M, Kaneko T, Matsubayashi J, Nagao T, Chiba H. Radiation-induced malignant fibrous histiocytoma of the maxilla. Odontology. 2011;99:203-8.

48. Adachi M, Iwai T, Hirota M, Tohnai I. Radiationinduced fibrosarcoma after radiotherapy for osteosarcoma in the mandibular condyle. J Craniofac Surg. 2012;23:e619-21.

49. Azevedo RS, Pires FR, Gouvêa AF, Lopes MA, Jorge J. Leiomyosarcomas of the oral cavity: report of a radiation-associated and a metastatic case. Oral Maxillofac Surg. 2012;16:227-32.

50. Brusić SK, Pusić M, Cvjetković N, et al. Osteosarcoma of the mastoid process following radiation therapy of mucoepidermoid carcinoma of the 
parotid gland-a case report. Coll Antropol. 2012;36(Suppl 2):223-5.

51. Kunert P, Matyja E, Prokopienko M, Marchel A. Radiation-induced tumours of meninges. Report on eight cases and review of the literature. Neurol Neurochir Pol. 2012;46:542-52.

52. Bingol UA, Arslan H, Cinar C. Postradiation sarcoma from a free flap. J Craniofac Surg. 2013;24: 2160-2.

53. Cai P, Wu Y, Li L, et al. CT and MRI of radiationinduced sarcomas of the head and neck following radiotherapy for nasopharyngeal carcinoma. Clin Radiol. 2013;68:683-9.

54. Santos Gorjón P, Gil Melcón M, Muñoz Herrera AM, Franco CF. Radiation-induced leiomyosarcoma of the posterior neck region. Acta Otorrinolaringol Esp. 2013;64:233-6.

55. Davies BW, Prescott CR, Said SA, et al. Radiationinduced dedifferentiated chondrosarcoma with orbital invasion. Ophthal Plast Reconstr Surg. 2014;30:205-8.

56. Sabater-Marco V, Zapater Latorre E, Martorell CM. Postradiation cutaneous pleomorphic rhabdomyosarcoma with extracellular collagen deposits reminiscent of so-called amianthoid fibers. J Cutan Pathol. 2014;41:316-21.

57. Song MJ, Song JS, Roh J-L, et al. Mdm2 and p53 expression in radiation-induced sarcomas of the head and neck: comparison with de novo sarcomas. Korean J Pathol. 2014;48:346-50.

58. Zhang G-B, Li J, Zhang P-F, Han L-J, Zhang J-T. Radiation-induced malignant fibrous histiocytoma of the occipital: a case report. World J Surg Oncol. 2014;12:98.

59. Chung J, Lee V, Tsang R, et al. Treatment outcomes of postradiation second head and neck malignancies managed by a multidisciplinary approach. Head Neck. 2015;37:815-22.

60. Wood J, Ver Halen J, Samant S, Florendo N. Radiation-induced sarcoma masquerading as osteoradionecrosis: case report and literature review. J Laryngol Otol. 2015;129:279-82.

61. Haidar YM, Rose MA. Radiation-induced carcinosarcoma of the submandibular gland: case report and review of literature. B-ENT. 2016;12:339-43.

62. Kim KS, Chang JH, Choi N, et al. Radiation-induced sarcoma: a 15-year experience in a single large tertiary referral center. Cancer Res Treat. 2016;48: 650-7.

63. Liao L-Q, Yan $\mathrm{H}-\mathrm{H}$, Mai J-H, et al. Radiation-induced osteosarcoma of the maxilla and mandible after radiotherapy for nasopharyngeal carcinoma. Chin J Cancer. 2016;35:89.

64. Marchitto G, Marci V, Berrone M, Pentenero M. Early arising sarcoma after adjuvant radiotherapy for oral squamous cell carcinoma. J Oral Maxillofac Surg. 2016;74(862):e1-8.

65. Rosko AJ, Birkeland AC, Chinn SB, et al. Survival and margin status in head and neck radiation-induced sarcomas and de novo sarcomas. Otolaryngol Head Neck Surg. 2017;157:252-9.

66. Yang Q, Mo Y, Zhao Q, et al. Radiation-induced sarcomas of the head and neck in post-radiation nasopharyngeal carcinoma. Radiol Med. 2017;122: 53-60.

67. Zhang P, Zhao L, Zhu Y-J, et al. Prognosis of fibrosarcoma in patients with and without a history of radiation for nasopharyngeal carcinoma. Ann Surg Oncol. 2017;24:434-40.

68. Rashidghamat E, Calonje JE. A case of radiationinduced osteosarcoma of the skull presenting as a cutaneous epidermotropic tumor with a short latent period. J Cutan Pathol. 2018;45:352-4.

69. Yang J, Gao J, Wu X, et al. Salvage carbon ion radiation therapy for locally recurrent or radiationinduced second primary sarcoma of the head and neck. J Cancer. 2018;9:2215-23.

70. Arai A, Ozawa S, Kinoshita S, et al. Radiation-induced angiosarcoma of the parotid gland after postoperative radiotherapy for hypopharyngeal carcinoma. Auris Nasus Larynx. 2019;46:940-5.

71. Kalra S, Grimer RJ, Spooner D, Carter SR, Tillman RM, Abudu A. Radiation-induced sarcomas of bone. J Bone Jt Surg Br. 2007;89:808-13.

72. Wu LC, Kleinerman RA, Curtis RE, Savage SA, de González AB. Patterns of bone sarcomas as a second malignancy in relation to radiotherapy in adulthood and histologic type. Cancer Epidemiol Biomarkers Prev. 2012;21:1993-9.

73. Cha C, Antonescu CR, Quan ML, Maru S, Brennan MF. Long-term results with resection of radiationinduced soft tissue sarcomas. Ann Surg. 2004;239: 903-9. 